\title{
Identification and characterization of differentially expressed genes during incompatible interaction between the foliar rust Melampsora larici-populina and poplar
}

\author{
Z.J. Chen, Z.M. Cao and Z.D. Yu \\ College of Forestry, Northwest A\&F University, Yangling, Shaanxi, China \\ Corresponding author: Z.M. Cao \\ E-mail: zmcao@nwsuaf.edu.cn
}

Genet. Mol. Res. 13 (1): 2082-2093 (2014)

Received April 29, 2013

Accepted November 12, 2013

Published March 24, 2014

DOI http://dx.doi.org/10.4238/2014.March.24.12

\begin{abstract}
Poplars are extensively cultivated worldwide, and their susceptibility to the foliar rust fungus leads to considerable damages in plantations. To better understand the molecular basis of poplar responses to the foliar rust, suppression subtractive hybridization was used to identify the potential important or novel genes involved in the Populus szechuanica infection by Melampsora larici-populina. A total of 515 expressed sequence tags (ESTs) with high quality were obtained and clustered into 66 contigs and 75 singletons to give a set of 141 uniESTs. The nucleotide Basic Local Alignment Search Tool (BLASTn) program was used to search for homologous sequences of the uniESTs in the GenBank database. Among them, 92.9\% showed homology to the poplar genome, and $2 \%$ showed similarity to the rust fungus genome. In addition, homology to known genes was analyzed by the BLASTx algorithm, and approximately $50 \%$ of the uniESTs were significantly homologous to genes encoding proteins with known functions. Based on a reverse transcription-polymerase chain reaction (PCR) and quantitative PCR approach, five uniESTs
\end{abstract}


were analyzed, and the results showed that the expression level of the thaumatin-like gene was highest at $72 \mathrm{~h}$ post-inoculation, and the pathogenesis-related protein 1 gene was highest at $48 \mathrm{~h}$ postinoculation. The information generated in this study provides new clues to aid in the understanding of incompatibility between poplar and the foliar rust.

Key words: Expressed sequence tags; Defense gene; Melampsora larici-populina; Populus szechuanica; Suppression subtractive hybridization

\section{INTRODUCTION}

Poplar plays an important role not only in economics as a naturally fast growing tree for wood production and in plant science as a model plant for perennial species but also in ecology as a sustainable bioenergy crop with a high carbon storage capacity (Rubin, 2008). Currently, Melampsora larici-populina represents the major threat of poplars in plantations worldwide, especially in Europe, North America, and China (Pinon and Frey, 2005; Cao et al., 2012). This biotropic fungus caused the most important foliar disease of poplar that greatly reduced the photosynthetic capacity, biomass production, and overall economic value of poplar trees in poplar plantation (Major et al., 2010; Covarelli et al., 2013; Wan et al., 2013). Breeding some resistance cultivars was the traditional method to reduce losses of this disease, but the long generation time of poplars made it impossible to match the evolutionary rates of the pathogen, which goes through several generations every year (Duplessis et al., 2009; Hacquard et al., 2011). Therefore, novel strategies to control this disease are needed, which essentially rely on a better understanding of the molecular mechanisms of the host and pathogen interaction.

Poplar-rust interaction is the emerging model of plant-pathogen interactions, especially in perennial plant species. Recently, the black cottonwood Populus trichocarpa "Nisqually-1" (http://genome.jgi.doe.gov/pages/blast.jsf?db=Poptr1_1) and M. laricipopulina (http://genomeportal.jgi-psf.org/pages/blast.jsf?db=Mellp1) have been sequenced by the Joint Genome Institute (JGI, Department of Energy, USA), and the analysis of these genomes is a great opportunity to identify fungal effector genes and poplar signaling genes during Populus-Melampsora interactions (Duplessis et al., 2009, 2011). To date, approximately 400 nucleotide-binding site leucine-rich repeat genes, representing a large class of plant resistance genes responsible for pathogen effector recognition and leading to complete resistance through effector-triggered immunity in many pathosystems (Dodds and Rathjen, 2010), were identified in the poplar genome by genome-wide analysis. This was twice the number reported in Arabidopsis thaliana (402 versus 178, respectively) (Hacquard et al., 2011). In addition to the large number of resistance genes, an expanded gene family encoding thaumatin-like proteins (TLPs), corresponding to the pathogenesisrelated (PR-5) proteins, illustrates an overrepresentation of defense-related genes in poplar with 42 genes identified in P. trichocarpa (Petre et al., 2011). In several plant-pathogen systems, a systemic response also occurs throughout the whole plant, but this phenomenon has not yet been clearly documented in poplar; these responses include $\mathrm{Ca}^{2+}$ influxes, activation of mitogen-activated protein kinase cascades, and generation of reactive oxygen 
species (Menges et al., 2008). Additionally, the transcriptome profilings of poplar-rust interactions in North America (Azaiez et al., 2009; Petre et al., 2012) and in Europe (Rinaldi et al., 2007) have been reported.

In order to better understand the mechanisms associated with the poplar genes potentially related to poplar defense response during the infection course of the foliar rust fungus M. larici-populina in China, which is critical to better control and management of this disease, we used Populus szechuanica as a tested host, a wild poplar species in China, which is resistant to most isolates of M. larici-populina, and has been widely used as differentiating host of the foliar rust races in the recent years (Liu et al., 2008; Chen et al., 2010; Cao et al., 2012). Therefore, we first constructed a suppression subtractive hybridization (SSH) library of the incompatible interaction between P. szechuanica and M. larici-populina, and then the dynamic expression of some rust-induced resistance genes were further confirmed by reverse transcription-polymerase chain reaction (RT-PCR) and quantitative PCR (qPCR).

\section{MATERIAL AND METHODS}

\section{Plant materials and inoculation procedures}

The avirulent isolate $\mathrm{Sb}_{052}$ of M. larici-populina (MLP) used in this study was from the College of Forestry at Northwest A\&F University, and all experiments were performed on 2-3-year-old cutting plants of $P$. szechuanica, which had been potted and grown in a glasshouse for 12 weeks. The urediniospores of the MLP isolate $\mathrm{Sb}_{052}$ were multiplicated on P. purdomii plant leaves, which are susceptible to most of Chinese MLP isolates, and collected from 12 to 20 days post-inoculation. The spores were dried and kept in a vacuum container at $4^{\circ} \mathrm{C}$. Fully expanded leaves from leaf plastochron index 5 to 8 were washed by clean tap water and spray inoculated on their abaxial surface with urediospore suspension $(1-2 \mathrm{mg} / \mathrm{mL})$ or with tap water as a control (mock-inoculated leaves). To facilitate pathogen infection, post-inoculated and mock-inoculated plants were placed in a growth chamber with high humidity at $25-27^{\circ} \mathrm{C}$ for $24 \mathrm{~h}$. Materials were harvested at different time points, including 6, 12, 24, 48, 72, 96, and $120 \mathrm{~h}$ post-inoculation (hpi), and the leaves were immediately snap-frozen in liquid nitrogen until RNA extraction.

\section{RNA extraction and SSH}

Total RNA was isolated from P. szechuanica Schneid. leaves harvested at different time points using the Trizol reagent (Invitrogen, Carlsbad, CA, USA), and mRNA was purified with the Oligotex mRNA Spin-Column Kit (Qiagen, Hilden, Germany) according to the manufacturer protocol. Briefly, tester RNA was prepared by pooling equal amounts of RNA from infection leaves harvested at 12, 24, 48, and $72 \mathrm{hpi}$, while driver RNA was pooled from the control leaves. The cDNA was synthesized using the SMART PCR cDNA Synthesis Kit (Clontech, Palo Alto, CA, USA), and SSH was carried out using the PCR-Select ${ }^{\mathrm{TM}}$ cDNA Subtraction Kit (Clontech) according to manufacturer instructions, with slight modifications. Driver and tester cDNAs were digested with the restriction enzyme RsaI and purified with the QIAquick PCR Purification Kit (Qiagen). The tester cDNA was subdivided into two pools and each was ligated with a different cDNA adaptor (supplied in kit). Finally, two 
rounds of hybridization and PCR amplification were carried out to normalize and enrich the differentially expressed sequence tags (ESTs) according to the manufacturer protocol. The subtraction efficiency was validated by PCR analysis using internal control $\beta$-actin primers (forward: CGTTTGGATCTTGCTGGTC, reverse: ACTTCTGGGCAACGGAATC). The subtracted PCR products were then inserted into the pGEMT Easy vector (Promega, Madison, WI, USA) and transformed into Escherichia coli Top10 competent cells, which were plated on solid Luria-Bertani (LB) supplemented with $50 \mathrm{mg} / \mathrm{L}$ ampicillin. The bacterial colonies were hand-picked from the plates and transferred to 96-well microtiter plates containing LB broth supplemented with $50 \mathrm{mg} / \mathrm{L}$ ampicillin and grown overnight at $37^{\circ} \mathrm{C}$. The colony PCR was performed to amplify the inserted ESTs by T7 and SP6 primers, and the positive clones were selected for sequence analysis by the DNA sequencer (Applied Biosystems 3730 Genetic Analyzer, USA).

\section{EST analysis}

The sequences were first screened against the UniVec database (http://www.ncbi.nlm. nih.gov/Vec-Screen/UniVec.html) and the E. coli genome sequence to remove vector, adaptor, and $E$. coli genome contamination. The resulting high-quality sequences were then clustered and assembled using the CAP3 program (Huang and Madan, 1999). In total, the unigenes were obtained and analyzed using nucleotide Basic Local Alignment Search Tool (BLASTn) with P. trichocarpa v1.1 (http://genome.jgi-psf.org/pages/blast.jsf?db=Poptr1_1) and M. laricipopulina v1.0 (http://genome.jgi-psf.org/pages/blast.jsf?db=Mellp1) from the JGI. The gene ontology (GO) annotations for the sequences were derived using their Uniprot annotation. The Uniprot database was used because it had extensive GO mapping. The GO annotation for level 2 was extracted for each library and used for further analysis (http://www.blast2go.com/ b2ghome).

\section{RT-PCR and qPCR}

Total leaf RNA was isolated by Trizol reagent (Invitrogen) from two tested populations. First-strand cDNA was synthesized with RT primer mixture (Oligo dT primer and Random 6 mers) using PrimeScript ${ }^{\mathbb{B}}$ RT Reagent Kit with gDNA Eraser (TaKaRa, Dalian, China) according to manufacturer instructions. The Populus ubiquitin gene was used as an endogenous control, and all primers for the candidate genes and Populus ubiquitin were designed by the Primer v5.0 software (PREMIER Biosoft International, Palo Alto, CA, USA), which were shown in Table 1. RT-PCR was conducted with the following program: an initial denaturation at $94^{\circ} \mathrm{C}$ for $5 \mathrm{~min} ; 25-30$ cycles of $94^{\circ} \mathrm{C}$ for $30 \mathrm{~s}, \mathrm{X}^{\circ} \mathrm{C}$ (see Tm in Table 1) for $30 \mathrm{~s}$, and $72^{\circ} \mathrm{C}$ for $1 \mathrm{~min}$; and a final extension at $72^{\circ} \mathrm{C}$ for $5 \mathrm{~min}$. The PCR products were detected on $2 \%$ agarose gels in $1 \mathrm{X}$ Tris, borate, ethylenediaminetetraacetic acid with ethidium bromide. qPCR was performed using a Bio-Rad CFX $96^{\mathrm{TM}}$ Real-Time Detection System and SYBR Green PCR Master Mix (TaKaRa) in a $20 \mu \mathrm{L}$ reaction. All reactions were carried out in triplicate. The PCR mix included $100 \mathrm{ng}$ cDNA for each candidate gene, 0.4 $\mu \mathrm{M}$ forward and reverse primers, and $10 \mu \mathrm{L} 2 \mathrm{X}$ SYBR Green PCR Master Mix. The cycle conditions were as follows: $95^{\circ} \mathrm{C}$ for $30 \mathrm{~s}$, followed by 40 cycles of $95^{\circ} \mathrm{C}$ for $10 \mathrm{~s}, \mathrm{X}^{\circ} \mathrm{C}$ (see Tm in Table 1) for $10 \mathrm{~s}$, and $68^{\circ} \mathrm{C}$ for $20 \mathrm{~s}$. The threshold cycle $(\mathrm{Ct})$ was defined as the 
cycle number at which the fluorescence intensity passed a predetermined threshold. The quantification of each candidate gene relative to the ubiquitin gene was calculated using the equation: $\mathrm{N}=2^{-\Delta \Delta \mathrm{Ct}}$.

\begin{tabular}{|c|c|c|c|c|}
\hline Gene name & Sequence No. & Primer sequences $\left(5^{\prime}-3^{\prime}\right)($ forward/reverse) & Size (bp) & $\operatorname{Tm}\left({ }^{\circ} \mathrm{C}\right)$ \\
\hline PR-5 & XM_002325041.1 & $\begin{array}{l}\text { CGAAACCAATGCCCTTACAC } \\
\text { CAATCACCTGTCTCGCACAT }\end{array}$ & 179 & 58 \\
\hline MIPS & XM_002310544.1 & $\begin{array}{l}\text { TGTCATCAAAGGCACCAAGA } \\
\text { AATACAAGCCAGAGCAAACAAG }\end{array}$ & 229 & 55 \\
\hline PR-1 & $\begin{array}{l}\text { XM_002333719.1 } \\
\text { XM_002300258.1 }\end{array}$ & $\begin{array}{l}\text { CATGTGTTGGTGGAGAATGC } \\
\text { TCGCGGAAATACATCGTTTC }\end{array}$ & 253 & 58 \\
\hline$\beta$-1,3-glucanase & $\begin{array}{l}\text { XM_002336667.1 } \\
\text { XM_002299755.1 }\end{array}$ & $\begin{array}{l}\text { CATTGCAAACAAGTATGTCT } \\
\text { AGCATCCGCCAATTTACAAG }\end{array}$ & 499 & 55 \\
\hline PAL & $\begin{array}{l}\text { EU603320 } \\
\text { CT029896 }\end{array}$ & $\begin{array}{l}\text { CTCATCTAGGTGGCTTCCTT } \\
\text { ATTTAGAGCCTCGCAACTTC }\end{array}$ & 305 & 55 \\
\hline Ubiquitin & XM_002321377.1 & $\begin{array}{l}\text { GCAGGGAAACAGTGAGGAAGG } \\
\text { TGGACTCACGAGGACAG }\end{array}$ & 151 & 58 \\
\hline
\end{tabular}

PR-5 = thaumatin-like protein gene; MIPS = myo-inositol 1-phosphate synthase gene; PR-1 = pathogenesisrelated protein 1 gene; $\beta$-1,3-glucanase = beta-1,3-glucanase; $\mathrm{PAL}=$ phenylalanine ammonia lyase; Ubiquitin $=$ endogenous control.

\section{RESULTS AND DISCUSSION}

\section{SSH libraries of incompatible populus-M. larici-populina interaction}

To isolate genes that were differentially expressed in the post-inoculation poplar, the SSH library was constructed using pooled mRNAs from poplar leaves that were infected by MLP and harvested at 12, 24, 48, and $72 \mathrm{hpi}$, and pooled mRNA samples from untreated leaves were used as drivers. The upregulated EST fragments were then cloned into the pGEM-T Easy vector, and a total of 550 clones from 600 randomly selected clones in the SSH library were confirmed to be recombinant by PCR with nested primers (supplied in kit). The recombinant plasmids of the 550 clones were isolated and sequenced. All sequences were retrieved in FASTA format with the BioXM software. Prior to assembly, sequencing reads were trimmed to remove vector and ribosomal sequences, poly(A/T) tails, and lowquality sequences, reducing the number of ESTs to 515. After trimming, the CAP3 program was used to assemble sequences at $98 \%$ sequence identity using a minimal overlap of 75 bp. The assembly resulted in 515 sequences formed by 66 contigs and 75 singlets. The longest uniEST was $1114 \mathrm{bp}$, and most of them were around 200 to $500 \mathrm{bp}$. The length of the singlets varied from 81 to $646 \mathrm{bp}$ with an average of $286 \mathrm{bp}$. The maximum singlets were grouped under 200-300 bp in length. The contig length ranged from 135 to $1114 \mathrm{bp}$ with an average of $392 \mathrm{bp}$, and $22.7 \%$ of the contigs extended from 300 to $400 \mathrm{bp}$. The number of ESTs grouped in each contig varied between 1 and 41 , with $84.8 \%$ of the contigs containing 2-10 EST members. The two most abundant uniESTs observed in the library included an EST that is most similar to plastidic aldolase from Ricinus communis (34 copies) and an EST similar to 1-aminocyclopropane-1-carboxylate oxidase from $P$. trichocarpa (41 cop- 
ies). Additionally, it has been reported that the $\mathrm{G}+\mathrm{C}$ content of a uniEST can be useful to distinguish plant-derived sequences from fungal sequences in mixed cDNA populations (Qutob et al., 2000). Our data showed that the average $\mathrm{G}+\mathrm{C}$ content of the poplar ESTs was 44.74\%, which is similar to that of soybean, rice, and Arabidopsis ESTs, but less than that reported in the wheat 3B chromosome exon-coding sequence (Arabidopsis Genome Initiative, 2000; Qutob et al., 2000; Choulet et al., 2010).

\section{Functional annotation and disease-resistant expression profiling}

Each of our uniESTs was compared to the Populus and M. larici-populina genome sequence through BLASTn in the JGI. Among them, 92.9\% (131 of 141 unique sequences) showed homology to the poplar genome, and 2\% (3 of 141 unique sequences) showed similarity to the rust fungus genome (Table S1). Furthermore, only contig 62 in the 10 uniESTs with no homology to the Populus genome exhibited homology (BLAST score $\geq 80$ ) to the Arabidopsis ESTs; the remaining small fractions (9 ESTs) consisted of those with a weak score $(<80)$ or no sequence similarity to any plant ESTs in the National Center for Biotechnology Information (NCBI) database. In addition, homology to known genes was analyzed by the BLASTx algorithm against the NCBI nonredundant protein database (E $\leq$ e- 5 cutoff) in the Blast2GO software (http://www.blast2go.com/b2ghome) (Conesa et al., 2005). Unknown unique sequences (no BLAST identification or "hit" returned) totaled $80(56.74 \%)$ of the 141 uniESTs (Table 2). We also analyzed the GO terms of 61 identified unigenes, which were organized into three categories representing molecular functions, biological processes, and cellular components (Gene Ontology Consortium, 2008). The sum of the poplar uniESTs per category did not add up to $100 \%$ because some sequences were classified into more than one category. Of the total unigene set, $51(83.61 \%)$ were annotated into the molecular function category (describing the biochemical activity performed by the gene product), $50(81.97 \%)$ into the biological process GO category (describing the ordered assembly of more than one molecular function), and 36 (59.02\%) into the cellular component GO category (describing subcellular compartments of a cell). Among the molecular functions, the most highly represented categories were binding (42\%) and catalytic activity (41\%) (Figure 1A). Among the biological processes, the largest proportion of functionally assigned unigenes fell into metabolic process, cellular process, response to stimulus, multi-organism process, and cell proliferation, while signaling, localization, developmental process, multicellular organismal process, cellular component organization, immune system process, biological regulation, and death comprised $22 \%$ of the sequences (Figure 1B). For the cell component category, almost all unigene sequences were annotated into the cell-cell subcategory; $10 \%$ were categorized into extracellular region, and 7\% were grouped into the macromolecular complex category (Figure 1C).

Transcripts were sampled from an immune-stimulated poplar leaf subtracted cDNA library by the EST approach in order to improve our studies of the P. szechuanica immune response to the entomopathogen MLP. From the ESTs involved in the poplar-MLP incompatible interaction, we identified several unigenes that were homologous to sequences of other species in this study (Table 2). Specific categories of defense response genes are summarized below. PR proteins are not present in healthy tissues, but they have been shown to accumulate after infection by pathogens, and the role of PR proteins was discussed in recent years (Sels et al., 2008). Compared with Arabidopsis, poplar has an abundance of defense-related genes, 
Table 2. Expressed sequence tag similarity analysis.

\begin{tabular}{|c|c|c|c|c|c|}
\hline Seq. name & Size (bp) & Description & E-Value & Identity & Copy \\
\hline Contig1 & 604 & DNA repair protein Sae2 [Cordyceps militaris] & $1.6 \mathrm{E}-54$ & $65.22 \%$ & 2 \\
\hline Contig2 & 329 & NBS-type disease resistance protein [Populus trichocarpa] & $1.3 \mathrm{E}-6$ & $57.00 \%$ & 3 \\
\hline Contig7 & 231 & $\begin{array}{l}\text { Ribulose bisphosphate carboxylase oxygenase } \\
\text { activase chloroplast [Ricinus communis] }\end{array}$ & $8.1 \mathrm{E}-36$ & $90.05 \%$ & 5 \\
\hline Contig8 & 1087 & Tropine dehydrogenase [Ricinus communis] & $4.0 \mathrm{E}-120$ & $83.40 \%$ & 11 \\
\hline Contig10 & 392 & Protein $[$ Populus trichocarpa $]$ & $5.4 \mathrm{E}-8$ & $47.80 \%$ & 4 \\
\hline Contig11 & 745 & Granulebound starch synthase [Solanum tuberosum] & $2.5 \mathrm{E}-61$ & $93.00 \%$ & 14 \\
\hline Contig12 & 1114 & Predicted protein [Populus trichocarpa $]$ & $2.1 \mathrm{E}-29$ & $76.88 \%$ & 15 \\
\hline Contig13 & 408 & Protein $[$ Populus trichocarpa $]$ & $9.2 \mathrm{E}-21$ & $51.25 \%$ & 4 \\
\hline Contig14 & 446 & Galactinol synthase [Populus trichocarpa $\mathrm{x}$ Populus deltoides] & $1.3 \mathrm{E}-74$ & $95.45 \%$ & 2 \\
\hline Contig15 & 229 & NBS-type disease resistance protein [Populus trichocarpa] & $1.1 \mathrm{E}-6$ & $57.00 \%$ & 15 \\
\hline Contig16 & 543 & Hypothetical chloroplast RF2 [Ruptiliocarpon caracolito] & $2.2 \mathrm{E}-38$ & $92.10 \%$ & 9 \\
\hline Contig23 & 489 & RRNA intron-encoded homing endonuclease [Medicago truncatula] & $7.5 \mathrm{E}-7$ & $69.75 \%$ & 3 \\
\hline Contig25 & 821 & Predicted protein [Populus trichocarpa] & $9.0 \mathrm{E}-6$ & $32.00 \%$ & 6 \\
\hline Contig37 & 480 & Protein [Populus trichocarpa] & $1.6 \mathrm{E}-28$ & $50.65 \%$ & 7 \\
\hline Contig38 & 342 & Protein [Populus trichocarpa] & $2.3 \mathrm{E}-8$ & $47.95 \%$ & 7 \\
\hline Contig39 & 409 & Protein [Populus trichocarpa] & $1.3 \mathrm{E}-29$ & $53.80 \%$ & 2 \\
\hline Contig41 & 498 & PSI P700 apoprotein A2 [Populus trichocarpa] & $6.2 \mathrm{E}-95$ & $99.45 \%$ & 10 \\
\hline Contig42 & 290 & Protein [Populus trichocarpa $]$ & 3.3E-18 & $56.35 \%$ & 2 \\
\hline Contig43 & 415 & Ycf2 [Cynomorium songaricum] & $2.1 \mathrm{E}-87$ & $98.20 \%$ & 2 \\
\hline Contig44 & 266 & $\begin{array}{l}\text { Pinus taeda } \text { anonymous locus cl1838contig1_02 } \\
\text { genomic sequence [Populus trichocarpa] }\end{array}$ & $1.2 \mathrm{E}-18$ & $95.15 \%$ & 5 \\
\hline Contig45 & 345 & Protein [Populus trichocarpa] & $2.5 \mathrm{E}-37$ & $81.70 \%$ & 14 \\
\hline Contig46 & 718 & 1-Aminocyclopropane-1-carboxylate oxidase [Populus trichocarpa] & $9.3 \mathrm{E}-82$ & $97.60 \%$ & 41 \\
\hline Contig47 & 304 & Phenylalanine ammonia lyase [Populus trichocarpa] & $2.2 \mathrm{E}-17$ & $82.38 \%$ & 10 \\
\hline Contig48 & 245 & Myo-inositol 1-phosphate synthase [Solanum tuberosum] & $7.2 \mathrm{E}-43$ & $95.90 \%$ & 8 \\
\hline Contig49 & 455 & Thaumatin-like protein [Nicotiana tabacum] & $3.6 \mathrm{E}-94$ & $80.65 \%$ & 9 \\
\hline Contig50 & 499 & Beta-1,3-glucanase [Populus tremula $\mathrm{x}$ Populus tremuloides] & $5.8 \mathrm{E}-100$ & $84.00 \%$ & 12 \\
\hline Contig51 & 455 & Pathogenesis-related protein $1[$ Populus tomentosa $]$ & $9.2 \mathrm{E}-77$ & $80.55 \%$ & 2 \\
\hline Contig52 & 456 & Pathogenesis-related protein 1 [Populus tomentosa] & $2.5 \mathrm{E}-74$ & $82.70 \%$ & 2 \\
\hline Contig53 & 362 & Protein $[$ Populus trichocarpa $]$ & $5.3 \mathrm{E}-49$ & $70.75 \%$ & 2 \\
\hline Contig54 & 350 & $\begin{array}{l}\text { Multidrug resistance protein ABC } \\
\text { transporter family [Populus trichocarpa] }\end{array}$ & $1.6 \mathrm{E}-64$ & $85.70 \%$ & 2 \\
\hline Contig55 & 206 & $\begin{array}{l}\text { Metallothionein-like protein } \\
\text { [Populus trichocarpa } \mathrm{x} \text { Populus deltoides }]\end{array}$ & $2.4 \mathrm{E}-31$ & $83.75 \%$ & 3 \\
\hline Contig56 & 261 & $\begin{array}{l}\text { Ribulose bisphosphate carboxylase oxygenase activase } \\
\text { chloroplastic-like [Ricinus communis] }\end{array}$ & $2.4 \mathrm{E}-28$ & $87.35 \%$ & 12 \\
\hline Contig58 & 337 & Plastidic aldolase [Ricinus communis $]$ & $3.6 \mathrm{E}-64$ & $98.85 \%$ & 34 \\
\hline Contig59 & 221 & Chloroplast photosystem I protein [Populus tremula $]$ & $2.7 \mathrm{E}-42$ & $99.90 \%$ & 10 \\
\hline Contig61 & 344 & Rubisco activase [Pinus halepensis] & $2.0 \mathrm{E}-54$ & $98.60 \%$ & 7 \\
\hline Contig63 & 353 & Calvin cycle protein CP12-like [Vitis vinifera] & $1.9 \mathrm{E}-58$ & $77.95 \%$ & 5 \\
\hline Contig64 & 466 & DNA damage-inducible protein 1 [Ricinus communis] & $3.8 \mathrm{E}-12$ & $86.21 \%$ & 4 \\
\hline Contig65 & 485 & Protein [Populus trichocarpa] & $3.8 \mathrm{E}-37$ & $81.75 \%$ & 4 \\
\hline Contig66 & 774 & 6-Phosphogluconate dehydrogenase [Vitis vinifera] & 9.9E-94 & $93.30 \%$ & 3 \\
\hline Singlet12 & 435 & Hypothetical chloroplast RF2 [Berberidopsis corallina] & $9.6 \mathrm{E}-73$ & $97.35 \%$ & 1 \\
\hline Singlet14 & 263 & Protein $[$ Populus trichocarpa] & $2.5 \mathrm{E}-52$ & $84.65 \%$ & 1 \\
\hline Singlet17 & 517 & Protein [Populus trichocarpa] & $1.7 \mathrm{E}-27$ & $50.80 \%$ & 1 \\
\hline Singlet 22 & 376 & Protein [Populus trichocarpa] & $1.9 \mathrm{E}-29$ & $59.90 \%$ & 1 \\
\hline Singlet 23 & 485 & Thaumatin-like protein [Nicotiana tabacum] & $5.7 \mathrm{E}-101$ & $79.05 \%$ & 1 \\
\hline Singlet24 & 311 & Trotein [Populus trichocarpa] & $7.9 \mathrm{E}-29$ & $64.33 \%$ & 1 \\
\hline Singlet 25 & 640 & Beta-1,3-glucanase[Populus tremula $\times$ Populus tremuloides] & $5.8 \mathrm{E}-129$ & $84.45 \%$ & 1 \\
\hline Singlet 26 & 355 & Glycolate oxidase [Mangifera indica] & $1.2 \mathrm{E}-47$ & $98.25 \%$ & 1 \\
\hline Singlet 27 & 289 & Granulebound starch synthase[Solanum tuberosum] & 4.53E-61 & $92.90 \%$ & 1 \\
\hline Singlet 28 & 400 & Photosystem II protein N [Oryza meridionalis] & 4.1E-23 & $94.15 \%$ & 1 \\
\hline Singlet40 & 220 & ATPase alpha subunit [Arabidopsis thaliana] & $2.9 \mathrm{E}-16$ & $96.75 \%$ & 1 \\
\hline Singlet47 & 566 & DNA repair protein SAE2 [Cordyceps militaris CM01] & $9.9 \mathrm{E}-55$ & $65.22 \%$ & 1 \\
\hline Singlet63 & 384 & Protein [Populus trichocarpa $]$ & 4.7E-15 & $46.95 \%$ & 1 \\
\hline Singlet65 & 163 & Xylem serine proteinase 1 [Ricinus communis] & $1.3 \mathrm{E}-27$ & $85.15 \%$ & 1 \\
\hline Singlet66 & 459 & Protein [Populus trichocarpa] & $1.5 \mathrm{E}-73$ & $80.70 \%$ & 1 \\
\hline Singlet67 & 614 & Galactinol synthase [Populus trichocarpa $\mathrm{x}$ Populus deltoides] & 3.1E-109 & $92.05 \%$ & 1 \\
\hline Singlet70 & 467 & 1-Aminocyclopropane-1-carboxylate oxidase [Populus x canadensis] & $6.1 \mathrm{E}-49$ & $78.65 \%$ & 1 \\
\hline Singlet71 & 403 & Pinus taeda anonymous locus cl1838contig 1 02 genomic sequence & $5.3 \mathrm{E}-18$ & $94.95 \%$ & 1 \\
\hline Singlet72 & 482 & Protein [Populus trichocarpa] & 3.7E-37 & $81.75 \%$ & 1 \\
\hline Singlet73 & 647 & Nucleotide-sugar transporter family protein [Arabidopsis thaliana] & $2.6 \mathrm{E}-61$ & $88.75 \%$ & 1 \\
\hline Singlet74 & 548 & Acyl:CoA ligase [Populus trichocarpa] & $4.0 \mathrm{E}-12$ & $90.67 \%$ & 1 \\
\hline Singlet75 & 357 & DEAD-box ATP-dependent RNA helicase [Glycine max] & $3.8 \mathrm{E}-42$ & $97.25 \%$ & 1 \\
\hline
\end{tabular}


A

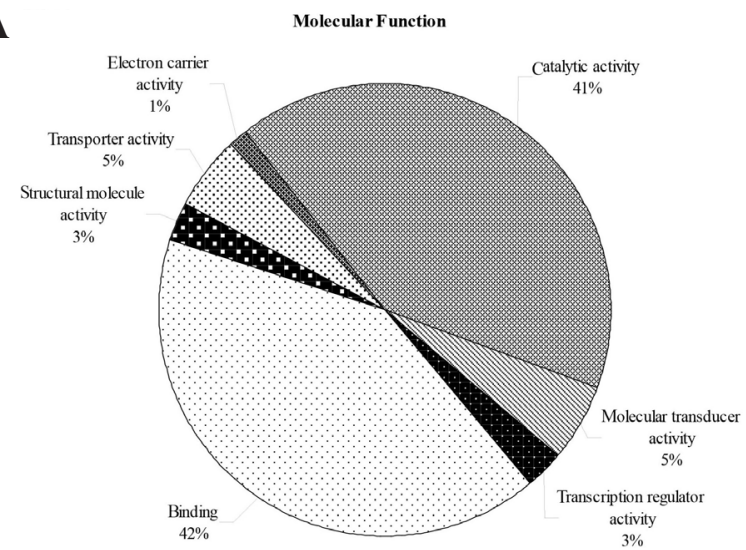

B

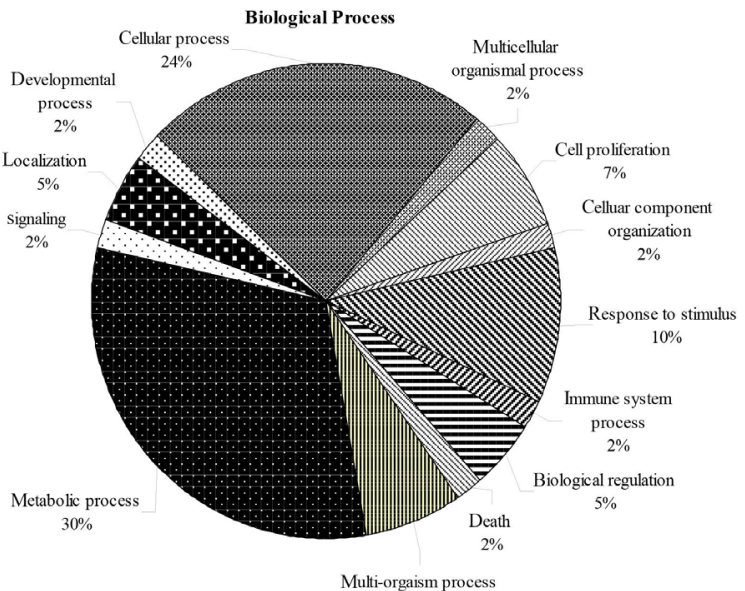

C

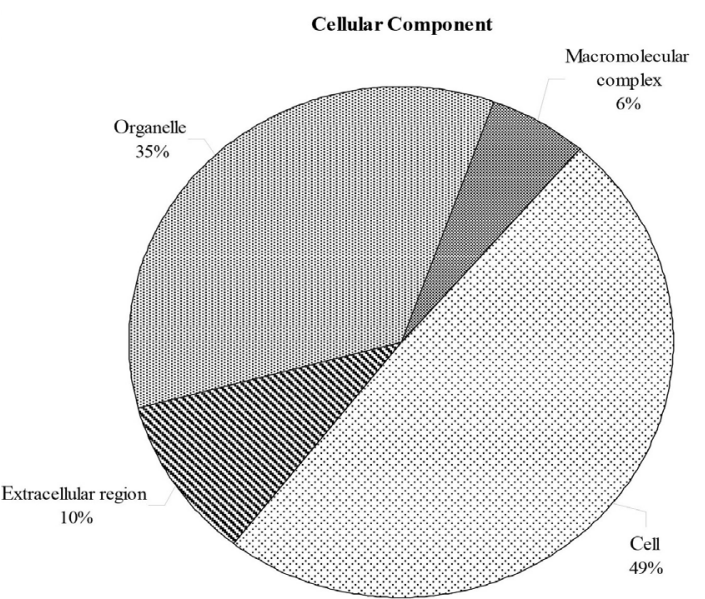

Figure 1. Gene ontology annotations and functional analyses of the unigenes with the automated Blast2GO software. A. Molecular function. B. Biological process. C. Cellular component. The percentage of gene transcripts in each group is listed. 
including thaumatin-like (PR-5), $\beta$-1,3-glucanases (PR-2), and pathogenesis-related protein 1 (PR-1), which likely represent poplar PR families (Tuskan et al., 2006). Consistent with Arabidopsis (Leon-Kloosterziel et al., 2005) and rice (Nakazaki et al., 2006) PR-1 proteins identified by PlantTribes, qRT-PCR analyses have shown that the Populus PR-1 ortholog is strongly upregulated after infection by M. larici-populina (Rinaldi et al., 2007) and Myrmicaria brunnea (Cheng et al., 2008). The PR-2 protein has $\beta-1,3$-endoglucanase activities, which likely hydrolyze fungal cell walls, while PR-5 proteins belong to the large TLP family, which also includes osmotins and osmotin-like proteins, which are reported to act against oomycetes and fungi (Leon-Kloosterziel et al., 2005; van Loon et al., 2006). In our study, contig 51 and 52 were two unigenes that were homologous to PR-1 of $P$. tomentosa, and contig 50 and singlet 25 had a similar sequence to that of a $\beta$-1,3-glucanase gene of $P$. tremula $\times$. tremuloides. Meanwhile, the sequences of contig 49 and singlet 23 were predicted to encode TLP because of their homology to the Nicotiana tabacum TLP gene. Considering that several unigenes encoding PR proteins were upregulated after MLP infection, the poplar PR genes can be expected to play important roles in pathogen defense. A previous poplar study also correlated increased lignin accumulation with phenylalanine ammonia-lyase (PAL) enzyme activities after inoculation with Entoleuca mammata, and the results indicated that the PAL gene was often reported as marker gene of lignin deposition (Bucciarelli et al., 1998). One uniEST in our paper, contig 47 (10 copies), was similar to the PAL gene of P. trichocarpa, which is indicative of a role in pathogen defense. Meyers et al. (2003) and Belkhadir et al. (2004) reported that the nucleotide-binding site and leucine-rich repeat protein resistance genes were the largest class of disease resistance genes, which play a crucial role in defending plants from a multitude of pathogens. Strikingly, a significant induction of contigs 2 and 15, which were assembled by 17 ESTs and predicted to be a $P$. trichocarpa nucleotide-biding site-type disease resistance protein, was also detected in the incompatible interaction.

\section{Validation of rust-regulated genes using cDNA RT-PCR and qPCR}

To confirm the results of the subtracted cDNA library, we randomly selected five upregulated clones (TLP, myo-inositol 1-phosphate synthase, PR-1, $\beta-1,3$-glucanase, and PAL) to analyze their expression patterns by RT-PCR during a time-course infection of $P$. szechuanica leaves at 12, 24, 48, 72, 96, and 120 hpi and mock-inoculated leaves $(0$ h), with ubiquitin as a positive control. The expression levels of all five clones from the subtracted cDNA library increased compared with those of the mock-inoculated leaves $(0 \mathrm{~h})$. The expression of $\beta$-1,3-glucanase was slightly detectable at $0 \mathrm{~h}$, and myo-inositol 1-phosphate synthase was expressed in both mock and post-inoculation samples. Obviously, the expression level of the TLP gene was highest at $72 \mathrm{hpi}$, and that of PR-1 was highest at 48 hpi (Figure 2). qPCR was also performed, and the results showed that expression level of the TLP gene was increased at the latter stage of the infection process, especially at $72 \mathrm{hpi}$. Compared with mock-inoculated leaves, PR-1 gene expression was upregulated greater than approximately 70- and 35-fold at 48 and 96 hpi (Figure 3). In contrast, qRT-PCR analyses showed that Populus TLP and PR-1 orthologs were strongly expressed after infection by M. larici-populina and M. brunnea at 48 hpi (Rinaldi et al., 2007; Cheng et al., 2008). The differences observed between our study and previous studies may have been because of differences in study design or differences in samples. 


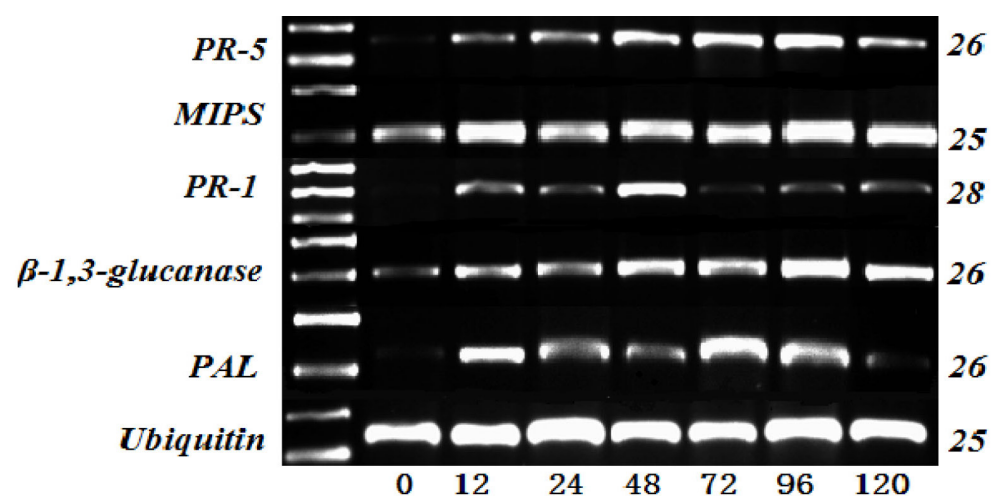

Figure 2. Suppression subtractive hybridization (SSH) results by RT-PCR during time-course infection of Populus szechuanica leaves at 12, 24, 48, 72, 96 and $120 \mathrm{~h}$ post-inoculation and non-inoculated leaves $(0 \mathrm{~h})$. Numbers of PCR cycles are listed on the right side. PR-5 = thaumatin-like protein gene; MIPS = myo-inositol 1-phosphate synthase gene; PR-1 = pathogenesis-related protein 1 gene; $\beta$-1,3-glucanase = beta-1,3-glucanase; PAL = phenylalanine ammonia lyase; Ubiquitin = endogenous control.
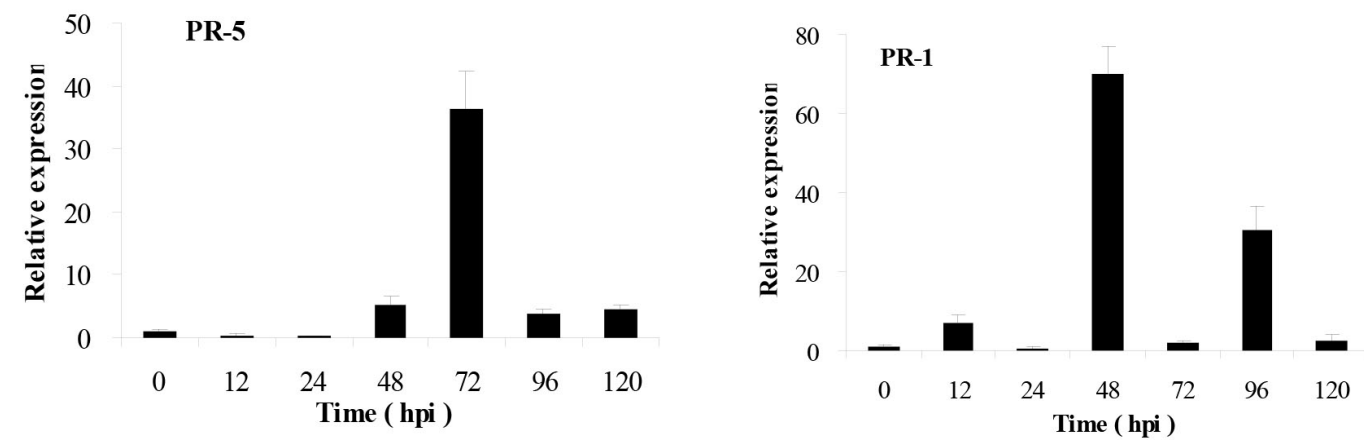

Figure 3. qPCR assay for the transcription levels of PR-5 and PR-1 during time-course infection of Populus szechuanica leaves at 12, 24, 48, 72, 96 and 120 hours pot-inoculation (hpi) and non inoculated leaves ( 0 h). PR-5= thaumatin-like protein gene; PR-1 = pathogenesis-related protein 1 gene; Ubiquitin = endogenous control.

In conclusion, we identified 141 differentially expressed sequences enriched in postinoculation poplar leaves using the SSH method. Based on GO annotation, 61 identified unigenes were organized into three categories representing molecular functions, biological processes, and cellular components, and five uniESTs were analyzed by RT-PCR and qPCR. The results showed that expression level of the TLP gene was highest at $72 \mathrm{hpi}$, and that of PR-1 was highest at $48 \mathrm{hpi}$, suggesting that at least the genes selected in this study may play important roles in pathogenesis.

\section{ACKNOWLEDGMENTS}

Research supported by the National Natural Science Foundation of China (\#30872027).

\section{$\underline{\text { Supplementary material }}$}




\section{REFERENCES}

Arabidopsis Genome Initiative (2000). Analysis of the genome sequence of the flowering plant Arabidopsis thaliana. Nature 408: 796-815.

Azaiez A, Boyle B, Levee V and Seguin A (2009). Transcriptome profiling in hybrid poplar following interactions with Melampsora rust fungi. Mol. Plant Microbe Interact. 22: 190-200.

Belkhadir Y, Subramaniam R and Dangl JL (2004). Plant disease resistance protein signaling: NBS-LRR proteins and their partners. Curr. Opin. Plant Biol. 7: 391-399.

Bucciarelli B, Jung HG, Ostry ME, Anderson NA, et al. (1998). Wound response characteristics as related to phenylpropanoid enzyme activity and lignin deposition in resistant and susceptible Populus tremuloides inoculated with Entoleuca mammata (Hypoxylon mammatum). Can. J. Bot. 76: 1282-1289.

Cao ZM, Du L, Wang QH and Yu ZD (2012). Genetic diversity of poplar rust fungus Melampsora larici-populina in China. Mycosystema 31: 510-522.

Chen ZJ, Cao ZM, Gou XQ and Jiang ZR (2010). Dynamic changes of active oxygen and related enzymes of the host in interaction between the poplar and Melampsora larici-populina. Sci. Silvae Sin. 46: 101-106.

Cheng Q, Cao Y, Pan H, Wang M, et al. (2008). Isolation and characterization of two genes encoding polygalacturonaseinhibiting protein from Populus deltoides. J. Genet. Genomics 35: 631-638.

Choulet F, Wicker T, Rustenholz C, Paux E, et al. (2010). Megabase level sequencing reveals contrasted organization and evolution patterns of the wheat gene and transposable element spaces. Plant Cell 22: 1686-1701.

Conesa A, Gotz S, Garcia-Gomez JM, Terol J, et al. (2005). Blast2GO: a universal tool for annotation, visualization and analysis in functional genomics research. Bioinformatics 21: 3674-3676.

Covarelli L, Beccari G, Tosi L, Fabre B, et al. (2013). Three-year investigations on leaf rust of poplar cultivated for biomass production in Umbria, Central Italy. Biomass Bioenergy 49: 315-322.

Dodds PN and Rathjen JP (2010). Plant immunity: towards an integrated view of plant-pathogen interactions. Nat. Rev. Genet. 11: 539-548.

Duplessis S, Major I, Martin F and Séguin A (2009). Poplar and pathogen interactions: insights from Populus genome wide analyses of resistance and defense gene families and gene expression profiling. Crit. Rev. Plant Sci. 28: 309334.

Duplessis S, Cuomo CA, Lin YC, Aerts A, et al. (2011). Obligate biotrophy features unraveled by the genomic analysis of rust fungi. Proc. Natl. Acad. Sci. U. S. A. 108: 9166-9171.

Gene Ontology Consortium (2008). The Gene Ontology project in 2008. Nucleic Acids Res. 36: D440-D444.

Hacquard S, Petre B, Frey P, Hecker A, et al. (2011). The poplar-poplar rust interaction: insights from genomics and transcriptomics. J. Pathog. 2011: 716041.

Huang X and Madan A (1999). CAP3: A DNA sequence assembly program. Genome Res. 9: 868-877.

Leon-Kloosterziel KM, Verhagen BW, Keurentjes JJ, VanPelt JA, et al. (2005). Colonization of the Arabidopsis rhizosphere by fluorescent $P$ seudomonas spp. activates a root-specific, ethylene-responsive $P R-5$ gene in the vascular bundle. Plant Mol. Biol. 57: 731-748.

Liu CM, Cao ZM and Yu ZD (2008). Physiological race indentification of Chinese Melampsora larici-populina. J. Northwest For. Univ. 23: 105-108.

Major IT, Nicole MC, Duplessis S and Seguin A (2010). Photosynthetic and respiratory changes in leaves of poplar elicited by rust infection. Photosynth. Res. 104: 41-48.

Menges M, Dóczi R, Okrész L, Morandini P, et al. (2008). Comprehensive gene expression atlas for the Arabidopsis MAP kinase signalling pathways. New Phytol. 179: 643-662.

Meyers BC, Kozik A, Griego A, Kuang H, et al. (2003). Genome-wide analysis of NBS-LRR-encoding genes in Arabidopsis. Plant Cell 15: 809-834.

Nakazaki T, Tsukiyama T, Okumoto Y, Kageyama D, et al. (2006). Distribution, structure, organ-specific expression, and phylogenic analysis of the pathogenesis-related protein-3 chitinase gene family in rice (Oryza sativa L.). Genome 49: 619-630.

Petre B, Major I, Rouhier N and Duplessis S (2011). Genome-wide analysis of eukaryote thaumatin-like proteins (TLPs) with an emphasis on poplar. BMC Plant Biol. 11: 33.

Petre B, Morin E, Tisserant E, Hacquard S, et al. (2012) RNA-Seq of early-infected poplar leaves by the rust pathogen Melampsora larici-populina uncovers PtSultr3;5, a fungal-induced host sulfate transporter. PLoS One 7: e44408.

Pinon J and Frey P (2005). Interactions Between Poplar Clones and Melampsora Populations and their Implications for Breeding for Durable Resistance. In: Rust Diseases of Willow and Poplar (Pei MH and McCracken AR, eds.). CAB International, Wallingford, 139-154. 
Qutob D, Hraber PT, Sobral BW and Gijzen M (2000). Comparative analysis of expressed sequences in Phytophthora sojae. Plant Physiol. 123: 243-254.

Rinaldi C, Kohler A, Frey P, Duchaussoy F, et al. (2007). Transcript profiling of poplar leaves upon infection with compatible and incompatible strains of the foliar rust Melampsora larici-populina. Plant Physiol. 144: 347-366.

Rubin EM (2008). Genomics of cellulosic biofuels. Nature 454: 841-845.

Sels J, Mathys J, De Coninck BM, Cammue BP, et al. (2008). Plant pathogenesis-related (PR) proteins: a focus on PR peptides. Plant Physiol. Biochem. 46: 941-950.

Tuskan GA, Difazio S, Jansson S, Bohlmann J, et al. (2006). The genome of black cottonwood, Populus trichocarpa (Torr. \& Gray). Science 313: 1596-1604.

van Loon LC, Rep M and Pieterse CM (2006). Significance of inducible defense-related proteins in infected plants. Annu Rev. Phytopathol. 44: 135-162.

Wan ZB, Li Y, Chen Y, Zhang X, et al. (2013). Melampsora larici-populina, the main rust pathogen, causes loss in biomass production of black cottonwood plantations in the south of China. Phytoparasitica 41: 337-344. 